\title{
Visual outcome after paediatric cataract surgery: is age a major factor?
}

\author{
Laurence C Lesueur, Jean L Arné, Eric C Chapotot, Dominique Thouvenin, \\ François Malecaze
}

\begin{abstract}
Aims-To determine functional results after unilateral and bilateral cataract surgery in children with different aphakic optical correction.

Methods-In this retrospective study, we evaluated visual acuity and binocular vision in 107 children who underwent cataract surgery during the 10 year period from 1985 to 1995. Aphakia was corrected by an intracapsular intraocular lens (IOL), spectacles or contact lenses.

Results-Mean visual acuity was $>20 / 40$ (<0.3 log MAR) with normal binocular vision in 58 children over 7 months of age operated on for bilateral cataracts. Pseudophakic eyes regained visual acuity $>20 / 63$ (<0.5 log MAR) more often $(90 \%)$ than aphakic eyes $(46 \%)(p<0.001)$. Binocular vision was also achieved more often after IOL implantation $(p<0.001)$. Visual outcome of early bilateral cataracts was less satisfactory in children with abnormal foveolar function. For 49 children who had surgery for unilateral cataracts, prognosis was poor when surgery was performed before the age of 7 months. For cataract surgery in older children $(\geqslant 7$ months) mean visual acuities were better with IOL implantation $(p<0.05)$.

Conclusion-Cataract surgery with unilateral and bilateral IOL implantation can provide a beneficial effect on final visual outcome in children who are operated on before abnormal foveolar function develops.

(Br F Ophthalmol 1998;82:1022-1025)
\end{abstract}

The aim of cataract surgery in children is to enable the acquisition or the restoration of a normal visual function. While contact lenses are a simple procedure to correct aphakia in children after cataract surgery, ${ }^{12}$ intraocular lenses (IOLs) have been quite successful and are used as a standard means of optically correcting vision. ${ }^{3-6}$ If cataract surgery fails in infants, the development of deprivation amblyopia determines final visual prognosis.

We retrospectively assessed final visual outcome in 135 children who underwent surgery for unilateral or bilateral cataracts, studying the effect of age at surgery and aphakia correction with or without intraocular lenses.

Laurence C Lesueur, MD, Service d'Ophtalmologie, Hôpital Purpan, Place du Docteur Baylac, 31059 Toulouse, France.

Accepted for publication 17 March 1998
Over a 10 year period, from January 1985 to December 1995, 165 eyes in 107 children aged 1 month to 16 years were operated on for uni- lateral or bilateral cataract and followed up at the ophthalmology unit, Purpan University Hospital, Toulouse, France.

Unilateral cataract surgery was performed in 49 children; 11 under the age of 7 months (group U1); 17 aged over 7 months (group U2); and 21 with unilateral traumatic cataract (group U3).

Bilateral cataract surgery was performed in 58 children; 21 under the age of 7 months (group B1) and 37 over 7 months (group B2).

Visual outcome was thus assessed for 49 eyes operated on for unilateral cataract and 116 eyes for bilateral cataracts.

In the 11 cases in group U1 (under 7 months) the diagnosis was total cataract and surgery was performed immediately upon diagnosis. For bilateral cataracts, the both eyes were operated during the same week.

The decision for surgery in children over 7 months of age was based on loss of best corrected visual acuity $(<20 / 40)$, onset of strabismus or nystagmus and loss of binocular vision.

Exclusion criteria were associated ocular anomalies (glaucoma, severe microphthalmia, posterior segment pathology, retinopathy of prematurity), systemic or mental disorders, surgery within the past 12 months and absence of follow up at the ophthalmology unit at the University of Toulouse Hospital.

SURGICAL TECHNIQUE

The surgical procedure consisted in an anterior limbal incision $(3.2 \mathrm{~mm})$, continuous anterior capsulorhexis, and phacoaspiration. Surgery was completed with peripheral iridectomy under miosis and single suture wound closure. Before the age of 5 years, primary posterior capsulotomy with a needle combined with central anterior vitrectomy through the same anterior limbal incision was performed to prevent secondary opacification of the posterior capsule. In the cases of implantation, a PMMA single piece intracapsular intraocular lens (IOL) measuring 5.5-7 $\mathrm{mm}$ in optical diameter was placed in an intracapsular position via an enlarged incision. ${ }^{7-9}$

Aphakia was corrected by spectacles or contact lenses in most of the children with early bilateral cataracts or when anatomical conditions were unsatisfactory for implantation (large rupture of posterior capsule, early miosis, or impossibility to place the IOL in an intracapsular position). Implantation was preferred in all cases of unilateral cataract and in cases of bilateral cataracts in children over 5 . 
Table 1 Distribution of functional results

\begin{tabular}{|c|c|c|c|c|c|c|c|c|}
\hline Cataract type & $\begin{array}{l}\text { Age at } \\
\text { surgery } \\
\text { (months) }\end{array}$ & $\begin{array}{l}\text { Follow up } \\
\text { (months) }\end{array}$ & $\begin{array}{l}\text { Mean visual } \\
\text { acuity } \\
\text { (Log } M A R)\end{array}$ & $\begin{array}{l}V A>1 \\
(\log M A R)\end{array}$ & $\begin{array}{l}V A 1-0.5 \\
(\log M A R)\end{array}$ & $\begin{array}{l}V A 0.5-0.2 \\
(\log M A R)\end{array}$ & $\begin{array}{l}V A<0.2 \\
(\log M A R)\end{array}$ & $\begin{array}{l}\text { Binocular } \\
\text { vision }\end{array}$ \\
\hline $\begin{array}{l}\text { U1 }(n=4) \\
\text { IOL }\end{array}$ & 4.3 & 55.5 & 0.925 & $2-50 \%$ & $1-25 \%$ & $1-25 \%$ & 0 & $1-25 \%$ \\
\hline $\begin{array}{l}\text { U1 }(n=7) \\
\text { No IOL }\end{array}$ & 3.9 & 37.6 & 1.029 & $4-57 \%$ & $2-29 \%$ & $1-14 \%$ & 0 & 0 \\
\hline $\begin{array}{l}\mathrm{U} 2(\mathrm{n}=15) \\
\text { IOL }\end{array}$ & 67.7 & 41.5 & 0.322 & $1-7 \%$ & $1-7 \%$ & $7-46 \%$ & $6-40 \%$ & $8-53 \%$ \\
\hline $\begin{array}{l}\text { U2 }(n=2) \\
\text { No IOL }\end{array}$ & 13 & 72 & 1.000 & $1-50 \%$ & $1-50 \%$ & 0 & 0 & 0 \\
\hline $\begin{array}{l}\text { U3 }(n=18) \\
\text { IOL }\end{array}$ & 91.5 & 39.1 & 0.230 & $1-6 \%$ & $1-6 \%$ & $3-16 \%$ & $13-72 \%$ & $16-89 \%$ \\
\hline $\begin{array}{l}\text { U3 }(n=3) \\
\text { No IOL }\end{array}$ & 100 & 30 & 0.540 & 0 & $2-67 \%$ & $1-33 \%$ & 0 & $2-67 \%$ \\
\hline $\begin{array}{l}\text { B1 }(n=6) \\
\text { IOL }\end{array}$ & 6.5 & 48.3 & 0.425 & 0 & $4-67 \%$ & 0 & $2-33 \%$ & 0 \\
\hline $\begin{array}{l}\text { B1 }(n=36) \\
\text { No IOL }\end{array}$ & 4.2 & 76.7 & 0.728 & $4-11 \%$ & $26-72 \%$ & $5-14 \%$ & $1-3 \%$ & $2-11 \%$ \\
\hline $\begin{array}{l}\text { B2 }(n=50) \\
\text { IOL }\end{array}$ & 79.9 & 39 & 0.266 & 0 & $4-8 \%$ & $29-57 \%$ & $17-33 \%$ & $23-77 \%$ \\
\hline $\begin{array}{l}\text { B2 }(n=24) \\
\text { No IOL }\end{array}$ & 27.1 & 102.2 & 0.607 & $3-12 \%$ & $10-42 \%$ & $9-38 \%$ & $2-8 \%$ & $5-42 \%$ \\
\hline
\end{tabular}

\section{AMBLYOPIA TREATMENT}

Amblyopia therapy was initiated immediately after surgery and adapted to visual gain. Patch occlusion during the day varied from 3 hours to 6 hours for the first month after surgery and was maintained thereafter if necessary.

VISUAL REVIEW

The Teller acuity cards and Snellen acuity test adapted for children of verbal or preverbal age were used to measure visual acuity. Binocular vision was assessed with the Wirt and Lang tests. One orthoptist consultant in our ophthalmology unit performed the visual review in all the children.

\section{STATISTICAL METHODS}

Visual acuities were converted into a log scale using the method outlined by Holladay and Prager. ${ }^{10}$ Quantitative data (visual acuity) were compared with the Student-Fisher test for sample sizes $\geqslant 10$ or with the Mann-Whitney $\mathrm{U}$ test for sample sizes $\leqslant 10$. Qualitative data (binocular vision) were analysed with the Yates's corrected $\chi^{2}$ test for sample size $\geqslant 5$ or

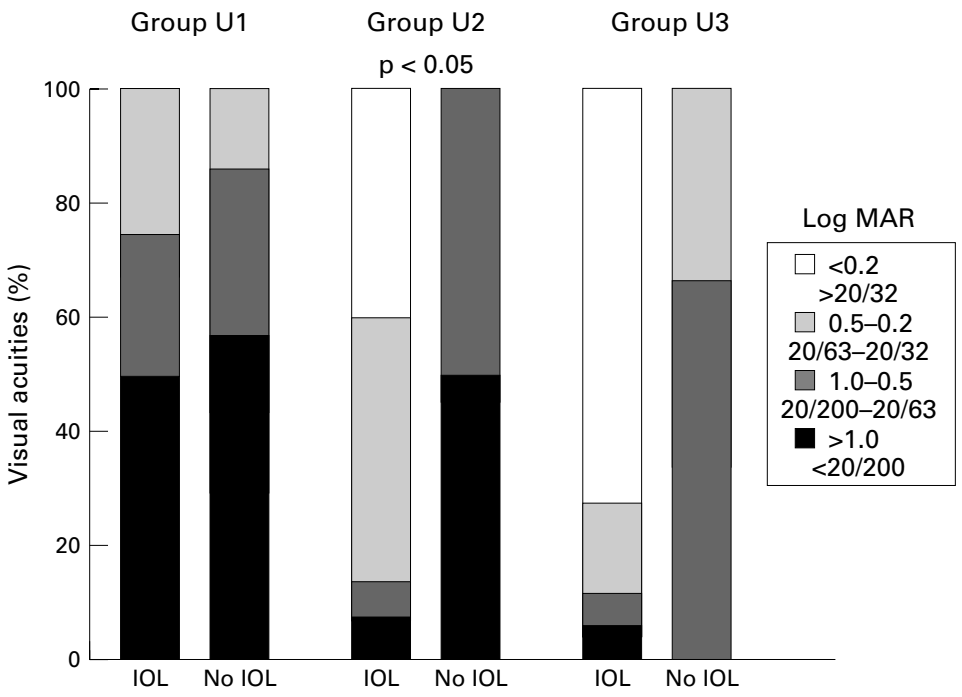

Figure 1 Unilateral cataracts. Distribution of visual acuities in pseudophakic (IOL) and aphakic (No IOL) eyes after surgery for early (group U1), late (group U2), and traumatic (group U3) cataracts. the exact calculation method (contingency table) for sample size $\leqslant 5$.

\section{Results}

Visual outcome after cataract surgery in 116 eyes is shown in Table 1 .

VISUAL ACUITY

The distribution of visual acuity after surgery for unilateral cataracts is illustrated in Figure 1. In group U1, early unilateral cataracts, an IOL was implanted in four of the 11 eyes. Mean visual acuities were poor for aphakic (1.029 log MAR) and pseudophakic eyes (0.925 log MAR) without significant difference. Visual acuity >20/63 (<0.5 log MAR) was recovered in only two eyes.

For late unilateral cataracts, group U2 results were better. IOLs were implanted in 15 of the 17 operated eyes. Mean post-surgery visual acuity (0.322 log MAR) was significantly higher $(p<0.05)$ in the 15 IOL pseudophakic eyes than in the two aphakic eyes ( $1 \log$ MAR). Although the sample size was insufficient to evidence a significant difference in this group, the proportion of pseudophakic eyes with a visual acuity $>20 / 32(<0.2 \log$ MAR) was high $(40 \%)$ compared with the aphakic eyes which were both $<20 / 63$ ( $>0.5 \log$ MAR). These latter two children were aged 13 months at surgery and contact lenses where chosen because satisfactory implantation is quite difficult to achieve at this age.

For group U3, traumatic cataracts, results were similar to those in group U2. IOLs were implanted in 18 of the 21 eyes. Mean visual acuity was better in pseudophakic eyes $(0.230$ $\log$ MAR) than in aphakic eyes (0.540 log MAR), although the significance threshold was not reached due to the small sample size. Again, there were more eyes with visual acuity $>20 / 63(<0.5 \log$ MAR) in the pseudophakic group $(88 \%)$ than in the aphakic group (33\%).

Figure 2 shows the distribution of visual acuity outcomes for bilateral cataracts. In group B1 of early bilateral cataracts (42 eyes), six eyes were implanted. The mean visual acuity was significantly higher $(p<0.05)$ in the pseudophakic eyes ( $0.425 \log$ MAR) than in 


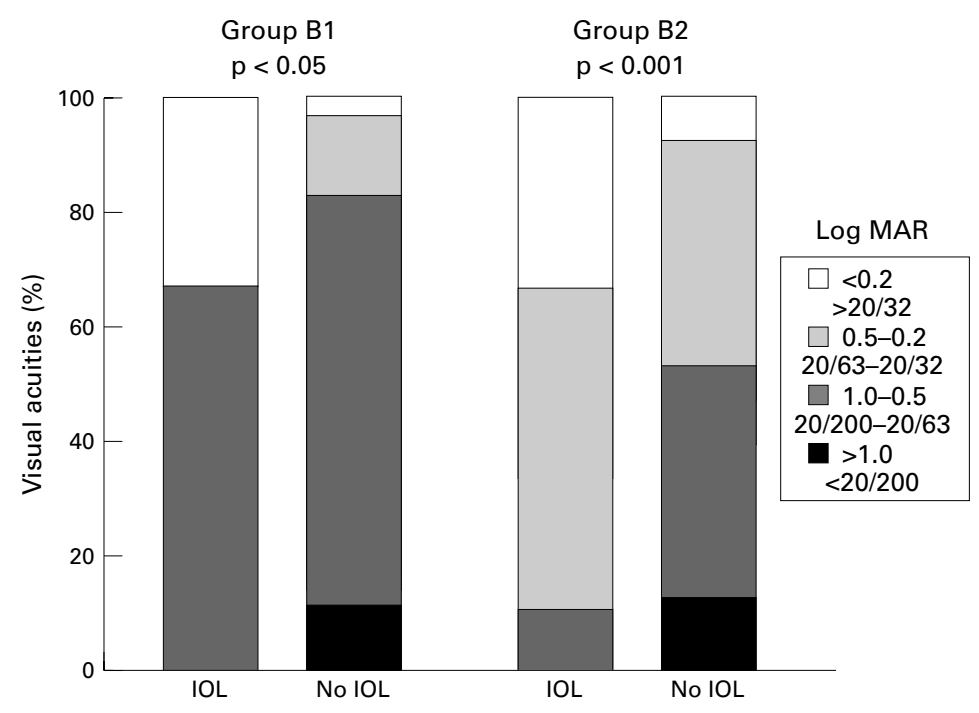

Figure 2 Bilateral cataracts. Distribution of visual acuities in pseudophakic (IOL) and aphakic (No IOL) eyes after surgery for early (group B1) and late (group B2) cataracts.

the aphakic eyes (0.728 log MAR). Visual acuity $>20 / 63(<0.5 \log$ MAR) was achieved more often in implanted eyes $(33 \%)$ than in non-implanted eyes (17\%).

The best visual outcomes were obtained in group B2, late bilateral cataracts. Of the 74 eyes operated on, 50 received an IOL. There was a highly significant difference $(p<0.001)$ between mean visual acuity in pseudophakic eyes (0.206 log MAR) and in aphakic eyes (0.607 log MAR). Moreover, the proportion of eyes with a visual acuity $>20 / 63(<0.5 \mathrm{log}$ MAR) was significantly higher $(\mathrm{p}<0.001)$ in the implanted eyes $(90 \%)$ than in eyes corrected with spectacles or contact lenses $(46 \%)$. Visual acuity $>20 / 32(<0.2 \log$ MAR) was achieved in $33 \%$ of the pseudophakic eyes.

BINOCULAR VISION

As shown in Figure 3, the presence of binocular vision for the unilateral cataract groups tended to vary with age at surgery (group U1: 25\%; group U2: $53 \%$; group U3: $85.7 \%$ ).

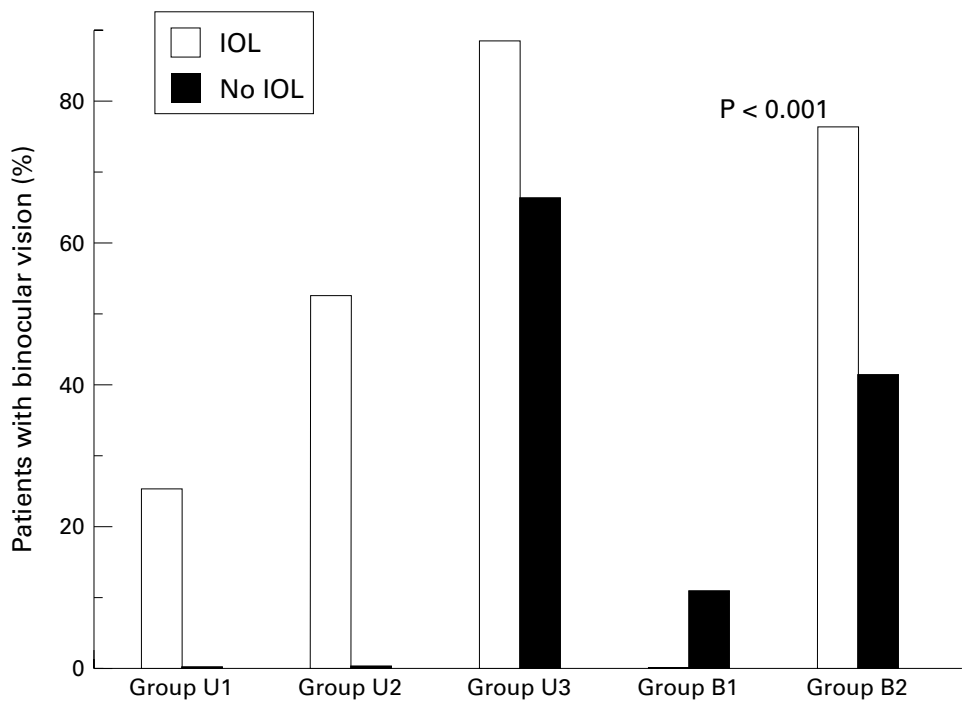

Figure 3 Binocular vision; difference in patients with (IOL) and without (No IOL) lens implantation.
Moreover, we found a difference between the age of patients in group U2 who received IOLs (67.7 months) compared with those who did not (13 months). This difference was also observed for binocular vision which was present in $53 \%$ of the patients with IOL implantation and never found in patients without the IOL procedure.

However, binocular vision was found more often in children in all three unilateral groups for whom aphakia had been corrected with an IOL. The results are similar in the bilateral groups where a highly significant difference $(p<0.001)$ was found for the pseudophakic eyes.

\section{Discussion}

Many studies reporting visual outcome after cataract surgery in paediatric patients focus on the type of cataract encountered (unilateral or bilateral) and the different methods used to correct aphakia. ${ }^{11} 12$ Lens implantation in paediatric aphakia remains a controversial issue. $^{13}$

In our study, mean visual acuity in early unilateral cataracts remained poor (0.981 log MAR), with no statistically significant difference between aphakic and pseudophakic eyes. Only one child treated for unilateral cataract recovered binocular vision; he had received an IOL. This lack of recovery of binocular vision is linked to the development of irremediable amblyopia in early unilateral cataracts. Many studies in the literature emphasise the advantage of very early surgery so visual acquisition can be achieved before abnormal binocular interaction develops. ${ }^{14}$ Wright et $a l^{15}$ have shown that sensorial fusion exists in $60 \%$ of children with eye surgery 9 weeks after birth. Birch et $a l^{16}$ found that visual acuity reached $20 / 40$ if surgery is undertaken before the age of 6 weeks. Moreover, Sinskey et $a l^{17}$ have demonstrated that IOLs can be implanted without major surgical complications as early as 17 days after birth. Gregg and Parks ${ }^{18}$ have also described the visual outcome of a 1 day old infant who achieved a visual acuity of 20/25 $(0.1 \log$ MAR) with binocular vision at 8 years. Finally, the work reported by Lewis et al ${ }^{19}$ also demonstrated the advantages of very early surgery owing to its effect on contralateral amblyopia induced by a central amblyogenic process.

For aphakia correction, visual outcome was better with a primary intracapsular implantation than with contact lenses although the difference between aphakic and pseudophakic eyes was not statistically significant.

In children with early bilateral cataracts, we found a significant difference $(p<0.05)$ in mean visual acuities in favour of lens implantation. In addition, only two children with aphakic eyes acquired binocular vision. It should be noted that in early bilateral cataracts, the existence of nystagmus plays a determining role in functional visual prognosis. The work of Robb and Petersen ${ }^{20}$ has shown poor visual results in children who had nystagmus before surgery. There are few data on implantation. Markham et $a l^{21}$ published their visual outcome results in 
infants operated on for early bilateral cataracts at 3 and 7 months of age. Their results were similar to ours for this type of cataract. Consequently, poor visual outcome following surgery for early bilateral cataracts would appear to be related to the existence of pre- and postoperative nystagmus. Since at the present time few results have shown long term benefit from IOL, the decision to implant in these children must be weighed carefully.

For late unilateral and bilateral cataracts, however, visual outcome is more satisfactory. In our study, mean visual acuities were always significantly higher in pseudophakic eyes. Likewise, the percentage of eyes with visual acuity >20/63 (<0.5 log MAR) was higher in cases with lens implantation, with a highly significant difference $(p<0.001)$ for late bilateral cataracts. Moreover, binocular vision was significantly more frequent in pseudophakic eyes. Gimbel et $a^{22}{ }^{23}$ operated 24 pseudophakic eyes in children over the age of 2 and found that visual acuity was $>20 / 40(<0.3 \log$ MAR $)$ 4 years after surgery in $79.2 \%$ of cases. Our results are in agreement with these findings.

Finally, Ben Ezra and $\mathrm{Paez}^{24}$ found foveolar fixing with a visual acuity $>20 / 40(<0.3 \mathrm{log}$ MAR) in nine children operated on for unilateral cataract with primary implantation performed after the age of $11 / 2$, without any major postoperative complications.

Our findings and those reported by Koenig et $a l,{ }^{25}$ who showed that $87 \%$ of children implanted with an IOL recovered visual acuity $>20 / 40$ ( $<0.3 \log$ MAR), also suggest that lens implantation would be the appropriate choice for traumatic cataracts if operating conditions are favourable and retinal damage can be avoided.

\section{Conclusion}

IOLs implantation is generally considered to be a safe surgical technique for the correction of paediatric aphakia. ${ }^{26}$ Visual outcome after surgical treatment of cataracts depends on the type of cataract encountered. For early unilateral and bilateral cataracts, good prognosis for visual acuity and binocular vision depends on early diagnosis and surgery before the development of abnormal foveolar function. Detection plays a crucial role here. The problem is different in late unilateral and bilateral cataracts because vision was acquired before cataract development. The question which is raised is one of identifying correct indications for lens implantation. The surgeon's decision should be based on personal experience and family consent after discussion with the medical team, essential for successful rehabilitation.

The mean visual acuities reported here after IOL implantation in children show that excellent visual outcome can be achieved with statistically significant differences between early and late bilateral cataracts, and late unilateral cataracts. Thus implantation would be indicated for unilateral and bilateral cataracts if surgery is undertaken before the development of abnormal foveal function. Foveal function and not age at surgery is the determining factor for visual outcome after paediatric cataract surgery.

The authors have no financial or proprietary interest in this study.

1 Dutton JJ, Slamovitch TH,Baker JD, et al. View points: visual rehabilitation of aphakic children. Surv Ophthalmol 1990;34:365-84

2 Neumann D, Weissman BA, Isenberg SJ, et al. The effectiveness of daily wear contact lenses for the correction of infantile aphakia. Arch Ophthalmol 1993;111:927-30.

3 Hiles DA, Hered RW. Modern intraocular lens IOLs in children with new age limitations. $\mathcal{F}$ Cataract Refract Surg 1987; 13:493-7.

4 Metge P, Cohen H, Chemila JF. Intracapsular implantation in children. Eur F Implant Refract Surg 1990;2:319-23.

5 Wilson ME, Bluestein EC, Wang XHW. Current trends in the use of intraocular lenses in children. 7 Cataract Refract Surg 1994;20:579-83.

6 Sinskey RM, Stoppel JO, Amin P. Long-term results of intraocular lens implantation in pediatric patients. $\mathcal{F}$ intraocular lens implantation in

7 Wang XH, Wilson ME, Bluestein EC, et al. Pediatric cataract surgery and intraocular lens Implantation cataract surgery and intraocular lens Implantation techniques: a

1994;20:607-9

Wilson ME, Apple DJ, Bluestein EC, et al. Intraocular lenses for pediatric implantation: biomaterials, designs, and sizing. F Cataract Refract Surg 1994;20:584-91.

9 Thouvenin D, Arne JL, Lesueur L. Comparison of fluorinesurface-modified and unmodified lenses for implantation in pediatric aphakia. 7 Cataract Refract Surg 1996;22:122631 .

10 Holladay JT, Prager TC. Mean visual acuity (letter). Am f Ophthalmol 1991;111:372-5.

11 Lesueur L, Thouvenin D, Arne JL. Résultats visuels et sensoriels du traitement chirurgical des cataracts de l'enfant; à propos de 135 cas. F Fr Ophtalmol 1995;18:667-77.

12 Thouvenin D, Lesueur L, Arne JL. Implantation intercapsulaire dans les cataractes de l'enfant;étude de 87 cas et comparaison à 88 cas sans implantation. f Fr Ophtalmol 1995; 18:678-87.

13 Lambert SR, Drack AV. Infantile cataracts. Surv Ophthalmol 1996;40:427-58.

14 Spielmann A. The fate of the "sound" eye in unilateral congenital cataracts. Eur F Implant Refract Surg 1990;2:245-8. 5 Wright KW, Matsumoto E, Edelman PM. Binocular fusion and stereopsis associated with early surgery for monocular congenital cataracts. Arch Ophthalmol 1992;110:1607-9.

16 Birch EE, Swanson WH, Stager DR, et al. Outcome after very early treatment of dense congenital unilateral cataracts. Invest Ophthalmol Vis Sci 1993;34:3687-99.

17 Sinskey RM, Amin PA, Lingua R. Cataract extraction and intraocular lens implantation in an infant with a monocular congenital cataract . F Cataract Refract Surg 1994;20:64751.

18 Gregg FM, Parks MM. Stereopsis after congenital monocular cataract extraction. Am f Ophthalmol 1992;114:314-17.

9 Lewis TL, Maurer D, Tytla ME, et al. Vision in the "good" eye of children treated for unilateral congenital cataract. eye of children treated for unilater
Ophthalmology 1992;99:1013-17.

20 Robb RM, Petersen RA. Outcome of treatment for bilateral congenital cataracts. Ophthalmic Surg 1992;23:650-6.

21 Markham RHC, Bloom PA, Chandna A, et al. Results of intraocular lens implantation in pediatric aphakia. Eye 1992;6:493-8.

22 Gimbel HV, Ferensowicz M, Raanan M, et al. Implantation in children. F Pediatr Ophthalmol Strabismus 1993;30:6979 .

23 Gimbel HV, Basti S, Ferensowicz M, et al. Results of bilateral cataract extraction with posterior chamber intraocular lens implantation in children. Ophthalmology 1997;104:1737-43.

24 Ben Ezra D, Paez JH. Congenital cataract and intraocular lenses. Am F Ophthalmol 1983;96:311-14.

25 Koenig SB, Ruttum MS, Lewandowski MF, et al. Pseudophakia for traumatic cataracts in children. Ophthalmology 1993;100:1218-24.

26 Ainsworth JR, Cohen S, Levin AV, et al. Pediatric cataract management with variations in surgical technique and aphakic optical correction. Ophthalmology 1997;104:1096101. 